\title{
Planning to deliberate thoroughly: If-then planned deliberation increases the adjustment of decisions to newly available information is
}

\author{
Johannes T. Doerflinger ${ }^{\mathrm{a}, \mathrm{b}, *}$, Torsten Martiny-Huenger ${ }^{\mathrm{c}}$, Peter M. Gollwitzer ${ }^{\mathrm{b}, \mathrm{d}}$ \\ a Graduate School of Decision Sciences, University of Konstanz, 78457 Konstanz, Germany \\ b Department of Psychology, University of Konstanz, 78457 Konstanz, Germany \\ c UiT The Arctic University of Norway, 9019 Tromsø, Norway \\ d Department of Psychology, New York University, 10003 New York, USA
}

Keywords:

Implementation intentions

Self-regulation

Poker

Decision making

Information processing

Escalation of commitment

\begin{abstract}
A B S T R A C T
Planning our actions in advance is an important means of action control and increases the likelihood of initiating intended actions at critical points in time (Gollwitzer, 1999; Gollwitzer \& Oettingen, 2016). In the current re search, we investigate whether planning to deliberate thoroughly can also increase the likelihood of deliberation when it is needed. As an increase in deliberation is often associated with more thorough use of available informa tion, we predict that planning to deliberate causes people to adjust their current course of action more closely to newly available information. We test this prediction in three experiments in which the participants are faced with the decision to continue with or disengage from a chosen course of action after new information has become available. The first experiment uses an established escalation of commitment paradigm (Study 1); the second and third experiment use a more naturalistic task based on the card game of poker (Studies 2 \& 3 ). In all three studies, planning to deliberate at a critical point in time by forming implementation intentions reduced the tendency to stick to a failing course of action, suggesting that plans to deliberate can be used to increase the likelihood of de liberation and thereby the effective processing of newly available information.
\end{abstract}

Every gambler knows

That the secret to survivin'

Is knowin' what to throw away

And knowin' what to keep

[Kenny Rogers, The Gambler]

Knowing what to keep and what to throw away is not only im portant for gamblers. In our everyday life, we often face decisions of whether to continue a currently pursued course of action or whether to change or even stop it altogether. Such decisions are complicated by the fact that changing or stopping a currently pur sued course of action often involves throwing away previous (time or money) investments which people are usually hesitant to do. Furthermore, and most important for our current work, continu ously changing information may make it hard to be prepared to make such a decision.

is The authors gratefully acknowledge financial support from the German Research Foundation (DFG) through the Research Unit "Psychoeconomics" (FOR 1882).

* Corresponding author at: University of Konstanz, Department of Psychology, P.O. Box 39, 78457 Konstanz, Germany.

E-mail address: johannes.doerflinger@uni-konstanz.de (J.T. Doerflinger).
When relevant information is available, being prepared is easy as one can plan specific future actions in advance and thereby in crease the likelihood of initiating the intended actions at critical points in time (Gollwitzer, 1993, 1999; Gollwitzer \& Oettingen, 2016). However, such planning gets difficult if circumstances are expected to unpredictably change over time, calling for flexible de cision making at a later critical situation. As some of us have sug gested previously in a theoretical paper (Martiny Huenger, Thürmer, Issa, \& Gollwitzer, 2011), we hypothesize that it may be advantageous to plan to deliberate thoroughly when expecting to face critical, decision requiring situations with an unpredictable information basis in order to prepare oneself for an informed and reflected future decision.

In our current research, we tested this idea of whether planning to deliberate influences subsequent decisions in a way that the de cisions are better adjusted to critical information information that was not available at the time of planning but became available only at a critical prospective situation. In the following, we will first introduce traditional action if then planning and then introduce our idea of planning a deliberation process. Finally, we will provide the rationale for why we expect that in certain situations deliberat ing thoroughly will lead to more optimal decisions compared to more spontaneous, unprepared decisions. 


\section{If-then planning}

Self instructions in the form of if then plans (e.g., "If I encounter sit uation S, then I will perform response R!") have proven to be an effec tive strategy to enhance goal striving (implementation intentions; Gollwitzer, 1999; Gollwitzer \& Sheeran, 2006). A person forming an im plementation intention identifies 1 ) a response with the potential to fa cilitate attaining a currently held goal, and 2) a critical situation (i.e., an opportunity or obstacle) in which the goal directed response is to be initiated. Such if then planning has been shown to increase the likeli hood of actually initiating the intended response when the critical situ ation is encountered. This effect is assumed to be the consequence of at least two mechanisms. First, specifying the critical situation in the if part of the plan results in a heightened mental accessibility of the critical situation (Achtziger, Bayer, \& Gollwitzer, 2012; Parks Stamm, Gollwitzer, \& Oettingen, 2007; Webb \& Sheeran, 2004; Wieber \& Sassenberg, 2006) which leads to an increased likelihood of detecting it when it is encountered. Second, formulating an if then plan creates a strong associative link between the critical situation and the goal di rected response (Bayer, Achtziger, Gollwitzer, \& Moskowitz, 2009; Gollwitzer \& Sheeran, 2006; Webb \& Sheeran, 2004, 2007). By means of spreading activation, this link increases the likelihood that the re sponse will be initiated when one faces the critical situation (see Gollwitzer, 2014, for an extended discussion of the mechanisms under lying if then planning).

Typically, implementation intentions are used to prompt specific re sponses. Such specific responses can range from actual physical actions (e.g., pressing a button; Cohen, Bayer, Jaudas, \& Gollwitzer, 2008) to purely cognitive responses (e.g., thinking of a word or a concept; Stewart \& Payne, 2008). In the current research, we aim to go beyond such specific responses to test whether planning to deliberate thor oughly actually increases the likelihood of initiating deliberation in the specified prospective situation.

It is noteworthy that such plans to deliberate contain the same basic components as classic implementation intentions and thus their effects are likely to be a result of the same psychological processes. We under stand deliberation as a cognitive response that needs to be initiated just like other cognitive responses (e.g., thinking of a certain word; Stewart \& Payne, 2008). As the working of implementation intentions is said to be associated with automaticity, this may seem in conflict with engag ing in deliberation, as reflecting pros and cons can be cognitively quite demanding. However, it is important to note that implementation in tentions automate the initiation of the respective responses after the initiation, they may have to run off controlled and effortful. In sum, it is not theoretically inappropriate to specify deliberation in the then part of an implementation intention; just like other complex responses (e.g. speaking up to racist remarks; Gollwitzer \& Brandstätter, 1997), deliberation can be expected to be initiated automatically and then pur sued in a controlled and effortful manner.

To test this experimentally, we asked our participants to specify an open ended deliberation in the then component of their if then plans rather than a specific response. As a testbed for our hypotheses we chose to use escalation of commitment task paradigms because in such tasks an optimal decision can only be made if information that was not available prior to the critical situation is successfully integrated. We will elaborate on this in the following section.

\subsection{Information use in commitment bias problems}

Once having themselves committed to a certain course of action (e.g., investing in a project), people do not like to make corrections, even if available feedback suggests that the current course of action is futile. This phenomenon is referred to as escalation of commitment (Staw, 1976) and it is known to occur in various contexts (e.g., with re gard to personal, business, or political decisions; Sleesman, Conlon, McNamara, \& Miles, 2012).
Self justification and loss aversion are two important mechanisms that drive escalation of commitment. For example, after deciding on a certain course of action for a project, one is committed to this course. Re ceiving negative feedback on the project's progress may call for making a course correction. However, making such a correction involves admit ting an error which conflicts with the need for self consistency and self justification. Changing one's course of action would imply either incon sistent choices and behavior or an unjustified commitment to the course of action in the first place (Bobocel \& Meyer, 1994; Brockner, 1992). Fur thermore, completely canceling a certain project because of a decreas ing probability of a successful completion includes accepting the sure loss of already invested money and resources another outcome that people are usually motivated to avoid (i.e., loss aversion; Soman, 2008). In sum, such motivations can lead people to quickly disregard and ignore negative progress information and continue with the previ ously chosen course of action (i.e., escalation of commitment; Sleesman et al., 2012).

We suggest that people can overcome this problem by applying a strategy that facilitates engaging in thorough deliberation at critical points in time. By "deliberation" we understand the investment of time and attention towards information processing regarding the task at hand, including feedback on goal progress. Many mechanisms that drive escalation of commitment (e.g., self justification motives; Bobocel \& Meyer, 1994; Brockner, 1992; and loss aversion; Soman, 2008) are working against processing available relevant feedback. For example, the motivation to avoid a sure loss drives the continuation of a project despite clear indications that the project is failing. Respecting relevant feedback information in the form of critical, verbal or numeric information requires time and effort directed towards the negative feedback (Birnboim, 2003). It has been shown in a recent meta analysis that an analytic thinking style (i.e., deliberation) can be beneficial for goal attainment if the context requires thorough information processing (Phillips, Fletcher, Marks, \& Hine, 2016). As we expect engaging in thor ough deliberation to provide the necessary time and effort, we hypoth esize an increased consideration of such feedback during deliberation which in turn should reduce the influence of other feedback indepen dent mechanisms (such as self justification motives).

So far, we have elaborated how deliberation may be instigated at critical points in time via if then planning. Furthermore, we provided an argument why deliberation at a critical point in time (e.g., when new feedback information becomes available) may decrease the ten dency to show escalation of commitment. In the final section before pre senting our experiments, we will summarize prior research combining if then planning and escalation of commitment paradigms to highlight how our current research goes beyond these studies to expand our un derstanding of how to improve decision making by planning.

\subsection{If then planning and escalation of commitment}

Henderson, Gollwitzer, and Oettingen (2007) have shown that im plementation intentions help to disengage from a failing course of ac tion by triggering the evaluation of one's current course of action. In one of their experiments, participants had to take a test in which differ ent strategies could be used to answer as many knowledge questions as possible. Before the test, participants were instructed to form either an action implementation intention that specified a concrete response to potential negative feedback ("If I receive disappointing feedback, then I'll switch to another strategy!"), or evaluate the effectiveness of the chosen strategy ("If I receive disappointing feedback, then I'll think about how things have been going with my strategy!"). Participants an swered knowledge related questions and received immediate (bogus) feedback about their performance after completing each item. Depend ing on the experimental condition, this feedback pointed to an increase or a decrease in performance. After having finished a given block of questions, the participants additionally received a summarized (bogus) feedback suggesting either good or poor performance. 
As expected, the results showed that action implementation inten tions ("then I'll switch to another strategy") led to changing the strategy after negative summarized feedback, independent of the recent perfor mance increase or decrease as indicated by performance feedback after each of the questions. In contrast, participants who had formed imple mentation intentions to evaluate how things have been going with the chosen strategy changed their strategy only when both the summarized feedback was negative and when they received information that there was a recent performance decrease. If there was feedback indicating a recent performance increase, participants were less willing to switch their strategy. These results provide initial evidence that implementa tion intentions can be used to induce a deliberative evaluation process about a specified topic and that this can lead to decision making that better respects the kind of feedback received.

In a more recent study, Wieber, Thürmer, and Gollwitzer (2015) have shown that implementation intentions can also be used to adopt a general neutral observer perspective. The authors used a hypothetical investment scenario task in which groups of participants playing the role of city councilors had to decide repeatedly how much money the community should invest in a public project (i.e., building a new kinder garten). In between the investment decisions, participants received feedback about the success of the project. The authors intended to trig ger a certain way of thinking: as neutral observers ("If we are about to make an investment decision, then we will judge the project as neutral observers who are not responsible for earlier decisions!"). In line with a self justification approach to escalation of commitment (Staw, 1976), the results showed that participants with the neutral observer perspec tive plan showed a reduced tendency to escalate commitment in this hypothetical group investment task.

Both the Henderson et al. (2007) and the Wieber et al. (2015) find ings suggest that if then planning can be used to direct one's delibera tion to certain critical content (i.e., evaluating one's current progress) and to influence the nature of an upcoming deliberation process (i.e., taking on a neutral observer perspective). Thus these studies provide a solid basis for our hypotheses that go two steps further. First, on the conceptual side, we test a content free if then plan that is supposed to induce thorough deliberation without any reference to what or how to deliberate. In other words, we aim to shift a decision maker's "mode of thought" from a default or a spontaneous manner of responding towards a more deliberate manner of responding.

Second we are going beyond the previously mentioned research with respect to the external validity of the used task paradigms. While choosing an established hypothetical investment scenario task (Staw, 1976) in our first study, in Studies 2 and 3 we picked a more naturalistic task paradigm: a card game. The card game of our Studies 2 and 3 was designed to represent a decision conflict parallel to that found in many hypothetical escalation of commitment paradigms, in which new information must be integrated to reach an optimal decision. How ever, using the card game with explicitly set rules and randomly gener ated information allowed us to investigate our hypotheses in an incentivized task with real consequences for the participants; when using hypothetical scenarios only false feedback is given.

\section{The present research}

The aim of the current studies is to test whether planning to deliber ate will increase the likelihood of thorough deliberation at the planned prospective event. Our indicators of deliberation are the increased con sideration of decision relevant information (feedback) and extended response times (Studies $2 \& 3$ ). One important premise of our studies using escalation of commitment task paradigms is that the unaltered continuation of a previously chosen course of action is a suboptimal de cision after receiving negative feedback. Negative feedback indicates that something is wrong and should be met with altering one's behavior (e.g., changing or terminating the current course of action). More specif ically, we hypothesize that motivational processes promote the unaltered continuation of a previously chosen course of action inde pendent of newly available information. However, after having formu lated a deliberation plan, the increased consideration of (negative) feedback should reduce this tendency and result in a revision of the pre viously made decision (i.e., less escalation of commitment). In Study 1, we used a well established escalation of commitment paradigm (Staw, 1976) with a single hypothetical decision in which we observed investment decisions after receiving positive or negative feedback concerning an initial decision. In Studies 2 and 3, we used a multi deci sion, non hypothetical, and incentivized task paradigm. This way, we tested our predictions in a more naturalistic setting with real conse quences. A deliberation plan "If [a critical situation] is encountered, then I will deliberate thoroughly!" was contrasted with both a no planning control condition with otherwise identical information (Studies 1 \& 3) and a spontaneity plan facilitating fast and intuitive responses but spec ifying the same critical situation in the if part of the plan (Studies $2 \& 3$ ).

\subsection{Study 1: investment scenario task}

The aim of Study 1 is to provide first evidence that planning to delib erate indeed increases the likelihood of deliberation at the prospective critical time. The deliberation should be evident by an increased consid eration of available feedback information and in turn a subsequent change in the course of action. To test this hypothesis, we used a task paradigm adopted from Staw (1976). Participants were presented with a fictitious scenario in which they were assigned the role of Chief Financial Officer of a company. Their task was to allocate money twice between two different divisions (consumer products and industrial products) of the company. After reading about the portfolio of the com pany, participants first decided which of the two divisions would re ceive a first investment of 10 million $€$. By choosing one of the two divisions, the participants decided on their initial course of action. After receiving either negative or positive feedback about the subse quent development of the previously chosen division, participants were asked to make a second investment decision in which they had to split 8 million $€$ between the two divisions. The amount of money invested in the previously chosen division served as the dependent var iable. In line with prior research (Staw, 1976; Wieber et al., 2015), we interpreted a relatively smaller investment after negative feedback in the previously chosen division as disengagement from the chosen course of action (i.e., as less escalation of commitment).

Prior to working through the scenario, participants in the control condition adopted the goal to make good investment decisions, where as participants in the deliberation plan condition adopted the goal to make good decisions and in addition formulated the plan "If the situation looks unfavorable, then I will deliberate thoroughly!" In addition to re cording the invested amount of money in the previously chosen divi sion, we asked the participants at the end of the experiment whether they would change their initial decision if they had the opportunity to do so. This categorical "yes no" question was supposed to assess the willingness to revise one's initial decision.

We predicted that increased consideration of the negative feed back in the deliberation plan condition should result in less invest ment in the previously chosen company division (i.e., less escalation of commitment) compared to participants without a de liberation plan and compared to participants receiving positive feedback about the status of their previously chosen division. We expected the same high investments in the positive feedback groups (regardless of the planning condition) and in the negative feedback group without the deliberation plan. The only group for which less investment was expected is the negative feedback group with the deliberation plan. In line with these predictions, we expected the highest of willingness to change as indicated by the willingness to change question at the end of the experiment in deliberation plan participants with negative feedback. 


\subsubsection{Method}

2.1.1.1. Participants and design. Power estimates were computed using the G*Power software (Faul, Erdfelder, Buchner, \& Lang, 2009; Faul, Erdfelder, Lang, \& Buchner, 2007) based on the Wieber et al. (2015) study. The suggested sample size was 80 participants to reach a power of 0.90 . Eighty five German speaking participants were recruited at the University of Konstanz. One participant did not provide data for the dependent variable and one participant gave an invalid answer (i.e., indicated an investment higher than the available money). Both participants were excluded from the analysis, resulting in a total sample of 83 participants ( 61 women) with a mean age of 23 (range 1857 , $S D=7.04$ ). Participants received $4 €$ or course credit and an additional payment that depended on their performance in a pre test task unrelat ed to the current study which they took part in after completing this ex periment. The study followed a 2 (plan condition: deliberation plan vs. no plan) $\times 2$ (feedback: positive vs. negative) between subjects design. The main dependent variable was the amount of money invested in the previously chosen division in the second investment decision.

2.1.1.2. Procedure. Upon entering the laboratory, the participants were randomly assigned to a plan and feedback condition and placed in indi vidual cubicles. Up to four participants took part in each session. Each session started with the plan instructions, which was directly followed by the investment scenario task. After completing the study, a pre test for an unrelated study was conducted before participants were debriefed and paid $4 €$ and a bonus for the unrelated pre test.

2.1.1.2.1. Plan conditions. Participants in both conditions received a sheet of paper that informed them about the study's general procedure and gave instructions to adopt the goal to make good decisions. After adopting this goal, participants in the deliberation plan condition were told that planning might facilitate goal attainment. Then they were instructed to form the plan "If the situation looks unfavorable, then I will deliberate thoroughly!" (original German text: "Wenn die Situation ungünstig aussieht, dann denke ich gründlich nach!"). Partic ipants had to mentally visualize this plan and write it down three times on a sheet of paper.

2.1.1.2.2. Investment scenario. The experiment was conducted as a paper and pencil experiment. The financial decision scenario was an adapted version of the paradigm used by Staw (1976), translated into German. It described the case of the hypothetical "Ankor AG," a major corporation in the IT business. The participants were asked to take on the role of a central executive who was making decisions about major financial investments. The economic success of the company had de clined over the last years, and according to the Board of Directors this was due to the rather weak research and development department of the company. Therefore, it was decided to invest $10 \mathrm{M} €$ in a research and development enhancement program. However, this money was to be invested in only one of two divisions: consumer products or industri al products. A short description of both divisions and tables illustrating their decline in profits were presented. Taking on the role of the central executive, the participants then chose the division to which the money should be given (i.e., initial investment decision) and supplied a short justification for that choice. The justification was requested to increase the commitment towards the chosen division.

2.1.1.2.3. Feedback. After having handed in their investment decision the participants were presented with new tables describing the situa tion of the two divisions five years after the initial investment. In the positive feedback condition, these tables indicated an increase in profit for the chosen division and a decrease in profits for the non chosen di vision, whereas the reverse pattern was presented in the negative feed back condition (i.e., decrease for the chosen division and increase for the non chosen division).

2.1.1.2.4. Dependent measure. Participants were then told that the corporation had decided to invest another $8 \mathrm{M} €$. This time, however, the participants could divide the money between the two divisions; the participants were asked to decide how to split the money and to write a short justification for their decision. The amount of money invested in the previously chosen division served as dependent variable. Finally, participants were asked the question "If you could make the first investment decision again, which department would you choose?". This additional categorical measure of escalation of commitment assessed whether participants were willing to change their initial course of action.

\subsubsection{Results}

An analysis of variance, including type of feedback (increase for con sumer and decrease for industrial products or increase for industrial and decrease for consumer products) and consumer vs. industrial division chosen, showed no significant effects of kind of feedback and initial choices ( $F s<1.00, p s>0.31$ ). It can be assumed therefore that whether participants initially chose the consumer versus industrial division had no effect on investment behavior. We thus ignored this factor in the main analysis.

2.1.2.1. Reinvestment in the previously chosen division. Fig. 1 illustrates the observed pattern of means for reinvestment in the chosen division. A 2 (plan condition) $\times 2$ (feedback) ANOVA revealed a marginally signifi cant main effect of the planning condition, indicating lower reinvest ments in the deliberation plan condition, $F(1,3)=2.80, p=0.098$, $d=0.37$. Feedback produced no statistically significant main effect, $F(1,3)=1.63, p=0.206, d=0.28$, and the interaction term did not reach significance either, $F(1,3)=0.32, p=0.573, d=0.12$.

As ANOVAs are not very sensitive in detecting the predicted pattern of results (expecting three conditions to be equal and only one condi tion to be different; Abelson \& Prentice, 1997; Rosenthal \& Rosnow, 1985), we conducted a planned contrast test to examine our specific prediction. The comparison of the negative feedback with deliberation plan condition to the other three conditions combined revealed a signif icant effect, $t(36.01)=2.26, p=0.03$, with a medium effect size $(d=$ 0.59 ). This finding suggests that participants in the negative feedback group with a deliberation plan invested less in the previously chosen $\mathrm{di}$ vision than participants in the other three groups. The latter groups did not differ in their investment as indicated by two further contrast tests showing that the positive feedback no plan control group did not differ from the positive feedback group with a deliberation plan, $t(40.97)=$ $0.70, p=0.49, d=0.21$, and finally, the positive feedback groups com bined did not differ from the negative feedback no plan control group, $t(51.65)=0.13, p=0.89, d=0.03$. Levene's test of homogeneity of

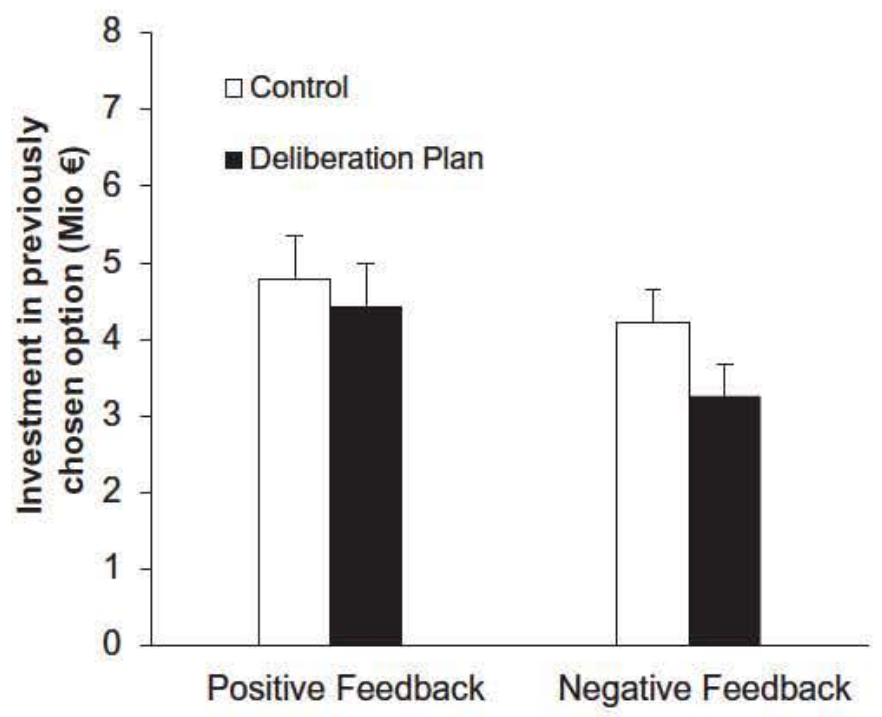

Fig. 1. Mean investment in previously chosen option per group by feedback and deliberation plan in Study 1 (error bars represent standard enrors). 
variance showed that variances differed between groups, $F(3,79)=$ $3.51, p=0.019$, and therefore statistics not assuming equal variances are reported.

2.1.2.2. Change of initial decision. A logistic regression analysis of the par ticipants' willingness to change the initial decision with the plan and feedback factors as well as their interaction as predictors revealed a marginally significant main effect of the plan, $\chi^{2}(1, \mathrm{~N}=82)=2.96$, $p=0.085$, and a significant main effect of the feedback factor, $\chi^{2}(1$, $\mathrm{N}=82)=12.26, p<0.001$. The interaction term however failed to reach significance, $\chi^{2}(1, \mathrm{~N}=82)=0.07, p=0.813$. Apparently, more participants were willing to change their first investment in the nega tive as compared to the positive feedback group as well as in the delib eration plan group (78.9\% in the negative feedback group, $52.4 \%$ in the positive feedback group) compared to the no plan control group (19.0\% in the negative feedback group, $4.7 \%$ in the positive feedback group).

\subsubsection{Discussion}

As expected, participants planning to deliberate thoroughly when ever the situation becomes unfavorable invested less money in the pre viously chosen company division after negative feedback compared to the other three groups (i.e., positive feedback with deliberation plan, positive feedback without deliberation plan, and negative feedback without deliberation plan). We interpret this decreased investment to be an indicator for an increased willingness to change one's previously chosen course of action. Apparently, the planned deliberation increased the consideration of the available information and reduced the tenden cy to continue with a previously chosen failing course of action. We did not find an increased investment but only continued investment in the negative feedback/no planning condition compared to the positive feed back condition. However, this is in line with other more recent research on escalation of commitment (e.g., Wieber et al., 2015). It did not under mine our expectation that only participants with a deliberation plan and negative feedback deviate from the investment decisions made by the participants receiving positive feedback (regardless of having a deliber ation plan or not) and those with negative feedback without a deliber ation plan.

Paralleling the decreased investment in the failing division, partici pants in the deliberation plan condition with negative feedback also contained the highest percentage of participants willing to change their initial decision. This finding provides additional evidence for the disengagement from a previously chosen course of action in the deliber ation plan and negative feedback condition.

Both analyses and interpretations, however, must be treated with caution, because the interaction terms of the plan and feedback factors did not reach significance. To fully support the hypothesis that the re sponse in the deliberation plan condition was indeed most sensitive to the feedback received, a significant interaction effect would need to be observed. Thus, the more appropriate interpretation of the present find ings is that participants in the deliberation plan condition invested less and were more willing to change their initial decision regardless of the feedback. Still, the observed results are first evidence that deliberation plans do influence decision making, and that they seem to reduce the tendency to stick to a previously chosen course of action. Additional studies are necessary however to explore whether this is a mechanism that is sensitive to the quality of feedback or not. The observed disregard for the feedback in the present study may have been caused by some in herent ambiguities of the hypothetical task paradigm used, and thus participants were more willing to change their initial choice and invested less in the previously chosen alternative in the deliberation plan condition regardless of the feedback information (i.e., positive or negative). A potential reason for this may be that whereas negative feedback was a clear indicator of a bad decision (the division in which the participant had invested lost money), positive feedback might have been experienced quite ambiguously. On the one hand, the investment did increase profit in the chosen division but on the other hand, not investing in the other division may have caused its financial decline, potentially leading participants into rethinking their previous decision.

In sum, our first study provides initial evidence that planning to en gage in deliberation does impact investment decisions. Because of limi tations in the task paradigm used, further studies are necessary to test whether the disengagement from a previously chosen course of action is in line with available positive/negative feedback. Study 2 is designed to test this in a novel, more naturalistic setting with real monetary con sequences depending on the participants' decisions.

\subsection{Study 2: variable investment poker task}

Study 2 extends the evidence that deliberation plans increase the likelihood of deliberation at the prospective critical time with regard to four important criteria: First, to avoid the disadvantages of relying on hypothetical decisions, in Study 2 we used a paradigm that allowed us to fully incentivize participants' decisions; in other words, the deci sions had real consequences for the participants. Second, because real card game situations are used in Study 2 as feedback, we can use the ob jectively calculated probability of losing a turn as a measure of feedback; as a consequence, in contrast to Study 1, in Study 2 there is no ambiguity and we do not rely on bogus feedback either. Third, as heightened acces sibility of the specified cue (Webb \& Sheeran, 2004, 2007) contributes to the effectiveness of if then plans and no such cue was specified in the no plan control condition of Study 1, we cannot ultimately credit the observed effect to the then part of the plan (deliberation). Thus, to methodologically disentangle the effect of the specified critical cue and the planned response, in Study 2 we compared two planning condi tions, both highlighting the same critical situation but with different intended responses (deliberation vs. spontaneity). As a consequence, differences between the two conditions can then be clearly attributed to the different planned responses. Finally, in addition to assessing deci sions, in Study 2 we recorded response times, which provided an addi tional, objective indicator for the amount of deliberation invested into each decision; in other words, we established a manipulation check.

In order to implement these changes, in Study 2 we introduce a novel task paradigm based on the card game Poker Texas hold 'em, the Variable Investment Poker Task (VIP Task). Poker has been examined in game theory as a zero sum game between $n$ players. Strategies and op timal behaviors in the game have been discussed for example by von Neumann and Morgenstern (1944/2007), and in a social psychological analysis of poker, Siler (2010) described it as a "fertile context to ob serve micro level economic and social behaviors in the context of risk and uncertainty" (p. 402). Poker is a competitive game in which the player is repeatedly confronted with making the decision to continue to invest money in a previously chosen course of action, most of the time in the absence of certainty about the outcome. It has to be noted that in our new poker task paradigm the information available to the participants (shown cards) corresponds directly to specific probabilities of losing a turn. In this sense, escalation in the VIP Task is related to heightened risk taking behavior. This is consistent with existing litera ture characterizing escalation as a disadvantageous form of risk taking (Brockner, 1992; Wong, 2005; Wong \& Kwong, 2007). All of this makes poker an ideal candidate for investigating decisions in escalation of commitment type of problems.

In our adaption of poker, participants played several rounds against a computer opponent. A round was won by the player whose cards had the highest value according to common poker rules. The computer op ponents' cards were visible to the participant players and the uncertain ty was introduced through covered cards which, when turned visible, contributed to both players' decks. Consequently, each additionally un covered card could change the likelihood of winning the current round for better or worse. The comparison of cards to determine the winner of 
the current round was only made when the participant had uncovered all four additional cards by investing in them.

Each turn started by uncovering two cards for each player, and the participants received a fixed amount of points that could be invested in the current round's sequential decisions. The participants first decid ed whether to play with the current cards or not by investing an initial small amount of points. This first decision parallels the initial invest ment decision in Staw like hypothetical escalation of commitment par adigms. If the participants decided to invest in the current cards, up to four decisions to invest in more cards versus opting out of the current round followed. These additional four decisions parallel the second in vestment decision in Staw like hypothetical paradigms and thus were used by us as the escalation of commitment variable. These investment decisions had the following characteristics: The initial decision to play with the current cards was made by the participants themselves, there fore opting out before all cards were uncovered equals revising one's initial decision. Even more important, for each additionally uncovered card an increasing amount of money had to be invested. Opting out of a current round because one considered the probability of winning to be too low meant to lose the money one had invested up to this point. Opting out was thus a decision to commit to a sure loss and against the still remaining possibility to win (Fig. 2).

The cards that were played with were not manipulated systemati cally, but rather presented randomly within the limits of an ordinary deck of cards (e.g., limited amount of cards per value and color). The likelihood of losing was calculated for each decision and thus represents a quasi experimental factor paralleling the positive or negative feed back in Staw like escalation of commitment paradigms. However, the feedback had to be actively deduced by the participants from their own cards, the opponents' cards, and the rules of the game. Similar to Study 1, before starting with the poker task, participants committed themselves to making good decisions. Then, the participants were asked to adopt either a deliberation plan ("If the situation looks unfavor able, then I will deliberate thoroughly!") or a spontaneity plan ("If the sit uation looks unfavorable, then I will decide quickly and spontaneously!").

In order to statistically reduce variance caused by inter individual differences, need for cognition (Cacioppo \& Petty, 1982), impulsivity (Dougherty, Mathias, Marsh, \& Jagar, 2005), numeracy (Lipkus, Samsa, \& Rimer, 2001; Peters et al., 2006), and experience with playing poker were assessed as control variables before the poker task. Need for cogni tion may represent a general tendency towards deliberation and thus reduce escalation of commitment. The reverse can be expected with regard to impulsivity. Numeracy represents the individuals' ability to handle numbers and probabilities; it seems possible that people scoring high in numeracy perform better in the required judgement of winning probabilities. Finally, experienced participants (i.e., people who play poker frequently) may outperform inexperienced participants.

Adapting our hypotheses to the new task paradigm, we predicted that deliberation plans should increase the likelihood of deliberation at the anticipated critical time, and the increased consideration of (neg ative) feedback (i.e., high probability of losing) should in turn reduce es calation of commitment. Thus, we predicted that in the deliberation plan condition, the participants' decisions to opt out of a round should be attuned more closely to the probability of losing. In other words, as suming that participants in general show a tendency to continue with their chosen course of action when the probability of losing rises, delib eration plan participants should change their (failing) current course of action and opt out earlier (i.e., less escalation of commitment) com pared to participants in the spontaneity plan condition. Additionally, assuming that response times are an indicator of the amount of deliber ation invested in a given decision, they should be longer for participants with a deliberation plan compared to participants with a spontaneity plan, and this should especially be the case when the probability of los ing is high as the critical anticipated situation is specified as an unfavor able situation.

\subsubsection{Methods}

2.2.1.1. Participants and design. Because the studies reported in this arti cle are the first to use the variable investment poker task, a priori power estimates were not feasible. Studies on implementation intentions have shown that they have typically a medium to large effect size (Gollwitzer \& Sheeran, 2006). We aimed at a sample size of at least 30 participants per experimental condition a number that has yielded adequate re sults in previous experimental studies on implementation intention. Sixty eight students of the University of Konstanz who did not partici pate in Study 1 participated in this study. Two participants admitted at the end of the experiment that they did not understand the ranking of card combinations (they systematically chose combinations with lower winning probabilities during the task over combinations with higher winning probabilities) and three participants did not comply with the planning instructions (one participant did not fill out the re spective manipulation check and two participants indicated different plans from those assigned in the instructions). These five participants

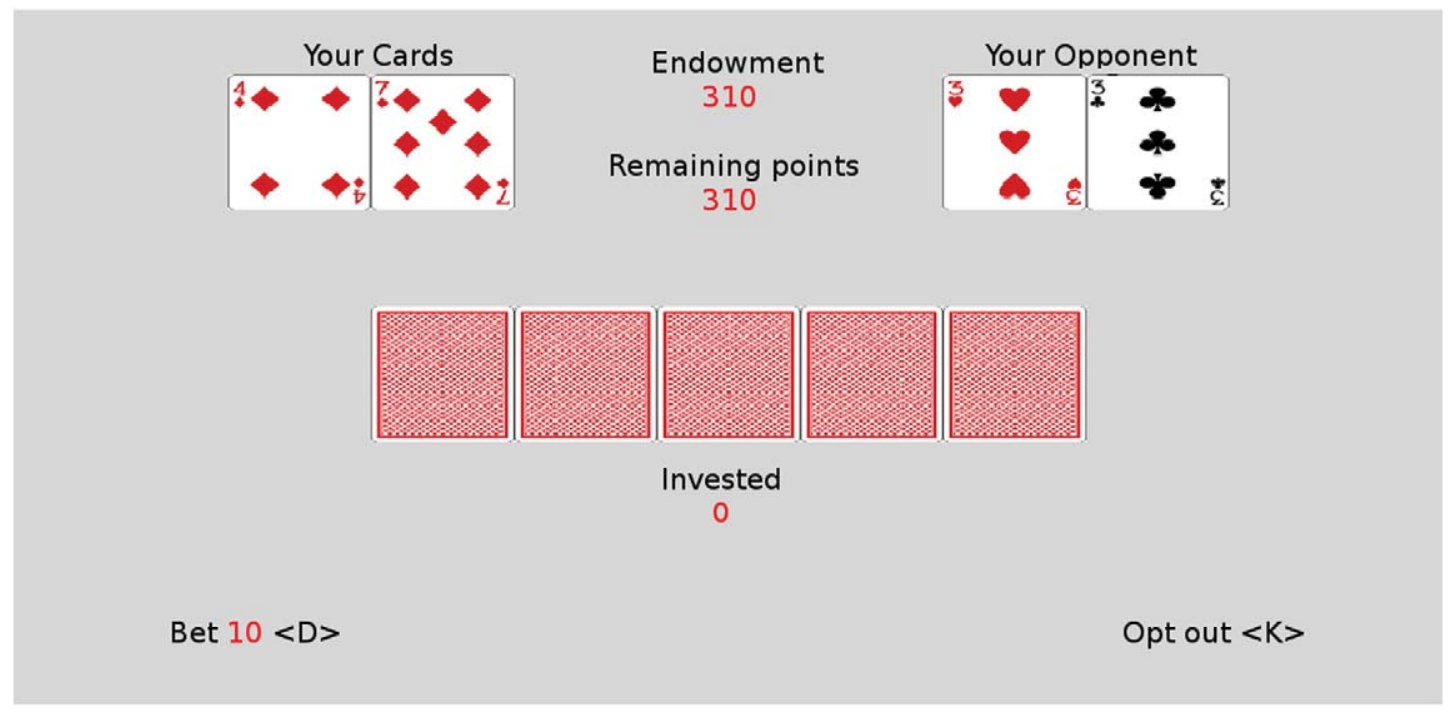

Fig. 2. Example of a round in Studies $2 \& 3$. The participant's cards are shown on the upper left side; the opponent's cards are on the upper right side. Before a bet has been made, the shared cards (in the middle of the screen) are shown facedown. The endowment is shown above the shared cards; the invested amount is shown below. Costs of betting can be seen in the lower left corner. In both studies a German version of the task was used. 
were excluded from the analyses and thus the total sample size is 63 ( 40 women, 1 person did not specify gender) with a mean age of 22.3 (range $=1739, S D=4.4$ ). The participants were reimbursed with 4 $€$ and an additional payment that depended on the points made in the card task. Planning was manipulated as a between subjects' factor (spontaneity vs. deliberation). The probability to lose in a given round of the game was determined by the randomly drawn cards (within nat ural game limits) in each trial and thus formed a continuous factor. The investment decisions (i.e., invest vs. opt out) served as the dependent variable.

2.2.1.2. Procedure. At the start of the experiment, participants were ran domly assigned to one of the two plan conditions (see below) and placed into individual cubicles. Up to four participants took part in each session. Each session started with the assessment of the control variables. In the next step, the plan conditions were established. This was directly followed by the card game task. Upon completion of the card game task, participants provided demographic information. Then they were debriefed and received payment depending on their perfor mance during the card game task.

2.2.1.2.1. Plan conditions. All participants received a short written de scription of the assigned implementation intention and the instruction to adopt such an implementation intention, visualize it, and write it down three times on a sheet of paper. Whereas participants in the delib eration plan condition were asked to adopt the plan, "If the situation looks unfavorable, then I will deliberate thoroughly!", participants in the spontaneity plan condition were asked to adopt the plan, "If the sit uation looks unfavorable, then I will decide quickly and spontaneously!" (German: "Wenn die Situation ungünstig aussieht, dann entscheide ich sofort spontan!").

2.2.1.2.2. Incentives. The main task of the experiment was a simulated card game that was played against the computer. The instruction ex plained that the game was played against a computer and that the pay ment for the experiment depended on participants' performance during the game. The task was incentivized so that each trial contributed to the participants' payment, received at the end of the experiment. Prior to the task, the rules of the game and the potential bonus payment were described in detail to the participants. Each trial could yield between 0 and 620 points. The experiment consisted of 40 trials, resulting in a maximum of 24,800 points. 3000 points were equivalent to $1 €$. The bonus was rounded to the nearest 10 cents. Thus, the bonus could the oretically range from $0 €$ to $8.30 €$; the lowest bonus payment in the ex periment was $3.30 €$ and the highest bonus turned out to be $5.70 €$.

2.2.1.2.3. Card game task. The task was based on the game of poker in its Texas hold 'em variant. The experiment was programmed using the experimental software PsychoPy (Peirce, 2007) and the programming language Python. A standard 52 card deck and the game's rules were implemented in the experimental software. The source code for the ex periment can be provided upon request from the first author. The task consisted of 40 trials, each of which involving up to five decisions. Of these five possible decisions the first decision was not made after having received feedback. The initial decision is thus different from the other decisions, because in the first decision the participants decided prior to any investment or commitment to playing a given game at all. In all subsequent steps, participants decided whether to continue with a hand they had already invested some points in. For these reasons, only the subsequent decisions speak to escalation of commitment. Therefore, only the latter four decisions served to assess whether the participants chose to disengage from the taken course of action or not.

At the beginning of each trial, two pairs of randomly drawn cards were presented below tags indicating which cards belonged to the par ticipant and which to the computer opponent. In addition to the cards, the starting amount of points for each round (310 points) was shown, as well as the points currently remaining, and the amount of points al ready invested. In the center of the screen, five cards were shown face down, which were shared and thus part of the playset of the participant and the computer opponent. Finally, the cost of investing in the next card was presented together with the key to be pressed to invest the points ("D") and the key to opt out of the current round ("K").

The general goal of the participants was to get as many points (i.e., final payment) as possible. If participants opted out in the first decision round, they kept their initial balance of 310 points. The initial decision to continue with the current deck of cards did cost 10 points and if partic ipants chose to invest in the current deck, the first shared card was re vealed. Participants could continue to invest until all five shared cards were revealed. Therefore, in any given round participants could make up to four decisions (investing or opting out) that were preceded by "feedback" (i.e., next card revealed). Each revealed card served as addi tional information on the probability of winning or losing the current round. The cost of revealing each additional card was increased by the factor 2 (i.e., 20, 40, 80, and 160). A participant consequently had to in vest all 310 points available to reveal all cards.

If a participant invested in and thus revealed all five additional cards, the best possible combination (according to standard poker rules) of five cards using the participant's initial two cards and the shared cards was compared to the best possible combination of five cards using the computer opponent's two initial cards and the shared cards. In the case of winning the comparison, the participant received double the amount of points invested (620 points). In the case of losing the com parison, the participant lost all points from the initial balance (i.e., re ceived 0 points). If the comparison ended in a draw, the participant received 310 points. In the case of opting out of a round at any given time, the participant lost the points invested so far and only kept the re maining points that were not yet invested. A sheet depicting the card combination rules was available for the participants during the poker game and could be used as reference throughout the game.

Dependent variables were the four possible decisions (investing or opting out) after the initial decision to play with the current cards, and response times for these decisions. Since one round ended as soon as the participant opted out, between 0 and 4 assessments would be performed during one round. The probabilities of losing at each given time depending on the participant's cards, the opponent's cards, and the revealed shared cards were estimated as frequentist probabilities by way of simulation. These probabilities were used as a quasi experi mental predictor. High losing probabilities represent negative feedback, whereas low losing probabilities represent positive feedback. Norma tively, participants should opt out if losing probabilities are high but in vest if they are low. Continued investments despite relatively high losing probabilities therefore qualify as evidence for disregarding the available feedback.

2.2.1.2.4. Control variables. Before the experimental manipulation of planning and starting the card game task, need for cognition (Cacioppo \& Petty, 1982) was assessed using the 18 items need for cog nition scale (Cacioppo, Petty, \& Feng Kao, 1984). As a general measure of impulsivity a shortened version of the GoStop impulsivity task para digm (Dougherty et al., 2005) was used. This computerized task was shortened to the duration of 3 min containing 150 trials. The percentage of false positive answers in the test was transformed into standardized scores. In addition, participants' ability to handle numbers and probabil ities was measured with the numeracy scale (Lipkus et al., 2001). As a measure for familiarity with the game, participants were asked to indi cate how often they had played poker during the previous year.

After providing demographic information, participants were debriefed about the purpose of the study and reimbursed with a fixed amount of $4 €$ and a bonus payment depending on their performance in the poker task.

\subsubsection{Results}

Tests on repeated measures were performed using mixed models. This was done with the lme4 package for R (Bates, Maechler, Bolker, \& Walker, 2015). For the categorical dependent measures (investment vs. opting out) mixed linear logit models were used, for continuous 
dependent measures (response times) we used mixed linear models. In these models, test statistics were approximated using the lmertest package for R (Kuznetsova, Brockhoff, \& Christensen, 2015). Random in tercepts for individual participants were included in the error term in all mixed models reported below.

2.2.2.1. Initial (non escalation) decision. To investigate participants' ini tial decisions, we conducted a mixed linear logit model with the proba bility to continue with the two initially revealed cards as the dependent variable, and planning condition, losing probability, and their interac tion as predictors. Not surprisingly, the analysis revealed a significant main effect of participants' losing probability, such that a higher proba bility of losing led to a lower probability to continue with the two initial ly revealed cards $(z=-11.04, p<0.001)$. The planning condition showed no significant main effect ( $z=1.21, p=0.227)$. In addition, the analysis revealed a significant interaction of planning condition and the probability of losing $(z=-5.01, p<0.001)$; we observed a stronger positive relation between the probability of losing and the probability of opting out in the deliberation plan condition as compared to the spontaneity plan condition. In other words, participants' deci sions to opt out were generally based on the probability of losing. Im portantly, however, the influence of the probability information on the decision to opt out was stronger for participants with a deliberation plan than for participants with a spontaneity plan.

2.2.2. Response times. Participants in the deliberation plan condition were expected to deliberate thoroughly whenever the situation looked unfavorable. One indication of such thorough deliberation should be longer response times. We thus expected to find longer response times in the deliberation plan condition compared to the spontaneity plan condition, especially when the probability of losing is high (i.e., critical cue of an unfavorable situation is encountered).

A mixed linear model with the plan condition and the probability of losing as predictors, and response times as the dependent variable sup ports this prediction. A significant main effect of probabilities of losing was found, demonstrating that longer response times correlate with higher probabilities of losing. Importantly, the analysis points to a signif icant interaction effect of the probability of losing and plan condition (see Table $2 \mathrm{a}$ for a summary of the model). The interaction parameter indicates longer response times in the deliberation plan condition com pared to the spontaneity plan condition, especially for high probabili ties of losing.

2.2.2.3. Control variables. In an initial analysis, we evaluated the influ ence of the control variables to assess which to include in the main anal ysis. In a mixed linear logit model including demographic and control variables, probability of losing, plan condition, the interaction of plan condition with probability of losing as well as the interaction terms of all control variables with plan condition as predictors and the probabil ity of investing as the criterion, the variables of age, gender, numeracy, need for cognition, and frequency of playing poker had no significant main effect or interaction effect with plan condition on participants' de cisions; $z<<0.90$, ps $>0.370$. However, there was a significant main ef fect of impulsivity $(z=2.41, p=0.016)$, indicating higher probabilities to invest for participants with higher impulsivity scores. Control vari ables with nonsignificant effects were not included in further analyses. See Appendix 1 for a summary of a model including these control variables.

2.2.2.4. Investment decisions. The main analysis predicted the probability of investing by the independent variables of planning condition, proba bility of losing, their interaction, and impulsivity as control variable in a mixed linear logit model, In this analysis, all decisions after the first ini tial decision to continue with the current deck of cards were included. Table 1a summarizes the model. Impulsivity was significantly related to probability of investing. In line with our reasoning that an unaltered
Table 1

Mixed linear logit models estimating probability of investing in Studies 2 and 3.

\begin{tabular}{|c|c|c|c|c|}
\hline Variable & B & SE B & $z$ & $p$ \\
\hline \multicolumn{5}{|l|}{ a) Study 2} \\
\hline Intercept & 3.99 & 0.13 & 30.29 & $<0.001$ \\
\hline Plan condition ${ }^{2}$ & 0.50 & 0.12 & 4.06 & $<0.001$ \\
\hline Losing probability & 3.89 & 0.15 & 24.58 & $<0.001$ \\
\hline Impulsivity & 4.09 & 1.22 & 3.35 & $<0.001$ \\
\hline Losing probability $\times$ plan condition ${ }^{2}$ & 0.66 & 0.16 & 4.21 & $<0.001$ \\
\hline \multicolumn{5}{|l|}{ b) Study 3} \\
\hline Intercept & 3.59 & 0.15 & 23.87 & $<0.001$ \\
\hline Dummy control $^{b}$ & 0.23 & 0.21 & 1.08 & $=0.279$ \\
\hline Dummy deliberation plan ${ }^{c}$ & 0.06 & 0.21 & 0.27 & $=0.782$ \\
\hline Losing probability & 2.86 & 0.19 & 14.70 & $<0.001$ \\
\hline Losing probability $\times$ dummy control ${ }^{\mathrm{b}}$ & 0.21 & 0.28 & 0.76 & $=0.449$ \\
\hline Losing probability $\times$ dummy deliberation plan ${ }^{c}$ & 0.53 & 0.27 & 1.98 & $=0.048$ \\
\hline
\end{tabular}

continuation of a previously chosen course of action is caused by moti vational processes that do not rely on effortful deliberate processing. higher impulsivity scores were related to a higher probability of investing. Moreover, the main effect of probability of losing was signif icant. A higher probability of losing predicted a lower probability of investing in the respective round of the game. Finally, the planning con dition produced no significant main effect.

Importantly, we observed a significant two way interaction effect of probability of losing and planning condition. This interaction is depicted in Fig. 3 and indicates a stronger negative relation between probability of losing and probability of investing in the deliberation plan condition compared to the spontaneity plan condition. In other words, partici pants with a deliberation plan compared to those with a spontaneity plan based their decisions to invest in additional cards more closely on their probability of losing (i.e., they stopped investing earlier if the prob ability of losing increased).

\subsubsection{Discussion}

In Study 2, we used a novel task paradigm based on a poker variant to investigate whether planning to deliberate increases the consider ation of available information and thereby decreases participants' ten dency to stick to a failing course of action. In this card game, participants could invest in additional cards to win points which were later refunded in real money. They had to decide whether to invest

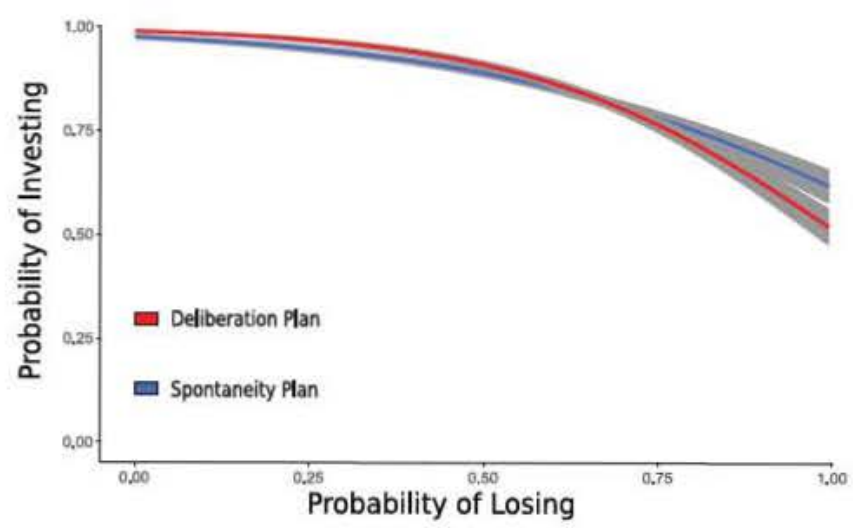

Fig. 3. Illustration of the linear mixed logit model estimating probability of investing in Study 2 depending on probability of losing, plan condition, and their interaction for al decisions after a first bet had been made. 
more points in order to win the current turn or opt out to save at least the remaining, not yet invested points. Both indicators, response times and the decisions made, suggest that participants planning to deliberate thoroughly whenever the situation looks unfavorable showed the ex pected effects. Compared to participants who planned to respond spon taneously, participants in the deliberation plan condition showed longer response times, especially in the critical situation specified in the plan (i.e., the unfavorable situation of a high probability of losing).

In the present studies, deliberation plans are not compared to a mere instruction to deliberate. Thus on the basis of our experimental design, we cannot distinguish whether deliberation was cue initiated or whether participants simply adopted a certain decision mode through out the task. However, participants did not generally take more time to respond in the deliberation plan condition. Rather, we observed an in teraction effect of the probability of losing and the planning condition, suggesting that participants in the deliberation plan condition only then took more time when the probability of losing was high. A high probability of losing was exactly the cue of the if then action plan (i.e., unfavorable situation). Thus, Study 2 provides initial evidence, that the deliberation was indeed a cue initiated response. We will return to this issue in the discussion of Study 3, where we change the specifica tion of the critical cue in the if then plan in order to provide further ev idence for the cue driven nature of the observed deliberation.

Most importantly, the actual investment decisions showed the ex pected effect of the plan to deliberate. Conceptually similar to our re sults from Study 1, compared to participants in the spontaneity plan condition, participants in the deliberation plan condition opted out of unfavorable situations (i.e., high probability of losing) earlier. Further more, in this study we also have evidence that participants in general aligned their decisions more closely to the probabilities of losing. In line with other escalation of commitment paradigms, each round started with an initial decision to continue with the current round or not. Interestingly, in this initial decision that required the lowest amount of points to be invested, we also observed that participants with a deliberation plan adjusted their decisions more closely to the probabilities of losing compared to participants in the spontaneity plan condition.

In sum, in this second study we provide evidence that planning to deliberate indeed has the effect that information available at the planned critical point in time is more likely to be integrated in one's de cision. Furthermore, keeping cue accessibility constant over the two planning conditions provides evidence that the observed patterns of ef fects are a consequence of a situation triggered response and not one of heightened cue accessibility. To validate the results of the novel para digm used in this study, in Study 3 we conducted a rather direct replica tion with a few methodological changes, for example, the inclusion of a no plan control condition and a different, less subjective trigger for the planned action.

\subsection{Study 3: replication using the VIP Task}

As in Study 2, the VIP Task was used to test the impact of deliberation plans on the use of feedback information. In our first two studies, the if specification of "unfavorable situation" entailed a negatively valenced connotation which may have contributed to the plans effectivity. To avoid such a potential confound, in Study 3 deliberation was linked to any newly revealed cards, irrespective of whether the situation was un favorable or not. Furthermore, we aimed to improve the study design by adding a neutral control condition. This way decisions can be compared to a default baseline. As in Study 2, we hypothesized that deliberation plan participants will align their choices closer to the probability of los ing a given turn. This means that as in Study 2 an interaction of proba bility of losing and the experimental conditions is likely to predict investments in the VIP Task. In contrast to Study 2, where deliberation was linked to unfavorable situations, we did not expect slower decision making in unfavorable situations for participants with deliberation plans because the critical cue in Study 3 referred to each revealed card. Thus, in terms of response times we do not expect an interaction of planning condition and probability of losing. Rather, response times are expected to be longer for those in the deliberation plan condition and shorter for those in the spontaneity plan condition.

\subsubsection{Methods}

2.3.1.1. Participants and design. One hundred and two participants ( 76 female) with a mean age of 19.2 (range $=1639 S D=3.75$ ) took part in the study. Participants were recruited from two groups: 50 par ticipants were students enrolled at the University of Konstanz and 57 were high school students in their last and second to last year visiting the University of Konstanz for an information day. Two of the high school students had to leave early and did not finish the experiment. Furthermore, three high school students left the form for the planning manipulation blank. These participants were not included in the final sample. Thus the sample included 52 high school students. As in Study 2 , the participants received $4 €$ and an additional payment that depended on their performance in the card game task. The planning manipulation served as a between subjects' factor (spontaneity vs. con trol vs. deliberation) and, as in the previous study, the probability to lose a given turn of the game formed a continuous predictor.

2.3.1.2. Procedure. Aside from the added control condition, the proce dure was the same as in Study 2 with minor changes (e.g., all but one of the control variables of Study 2 were included). Participants in the control condition were informed that explicit goals help to achieve bet ter performance. They were instructed to adopt the goal: "I want to make as much money in this experiment as possible!" Instructions for the plan conditions were the same as for the control condition, with the exception that participants received in addition to the instruction to adopt the goal of making money the instruction to make an if then plan for the next task. The plan assigned to participants in the delibera tion plan condition read: "If a new card is revealed, then I will deliberate thoroughly!" The plan for the participants in the spontaneity plan con dition was: "If a new card is revealed, then I will decide quickly and spontaneously!" As in both previous experiments, the participants in the planning conditions were instructed to mentally visualize their plan and write it down three times on a sheet of paper. Then, partici pants completed 40 trials of the poker card game following the same in structions as given in Study 2.

\subsubsection{Results}

As in Study 2, mixed linear logit models were calculated to investi gate the impact of deliberation plans and spontaneity plans on invest ment decisions, and mixed linear models were used to analyze response times; random intercepts for individual participants were in cluded in the error term in all models.

2.3.2.1. Initial (non escalation) decision. A mixed linear logit model re vealed that participants were generally more reluctant to play bad hands than good ones (i.e., when probability of losing was high), as can be seen in the significant main effect of probability of losing $(z=-7.04, p<0.001)$. Analyzing the main effect of the experimental conditions revealed that participants in the control group were less like ly to make an initial investment than participants in the spontaneity plan group $(z=-2.13, p=0.033)$; there was no difference between the deliberation plan group and the spontaneity plan group in their ini tial decision $(z=1.62, p=0.104)$. There was a significant interaction of planning conditions and probability of losing for predicting participants' choice of whether to play a given hand or not. In particular, participants in the spontaneity plan condition were more willing to continue with a bad hand than the control group $(z=-2.95, p=0.003)$. The compar ison of the spontaneity plan group and the deliberation plan group did not reach significance $(z=-1.48, p=0.139)$. 
Table 2

Mixed linear model estimating response times in Studies 2 and 3.

\begin{tabular}{|c|c|c|c|c|c|}
\hline Variable & $B$ & SE B & $d f$ & $t$ & $p$ \\
\hline \multicolumn{6}{|l|}{ a) Study 2} \\
\hline Intercept & 3.05 & 0.23 & 77 & 13.00 & $<0.001$ \\
\hline Plan condition ${ }^{a}$ & 0.08 & 0.23 & 77 & 0.34 & 0.732 \\
\hline Losing probability & 1.07 & 0.17 & 10,800 & 6.10 & $<0.001$ \\
\hline Losing probability $\times$ plan condition ${ }^{\mathrm{a}}$ & 0.64 & 0,17 & 10,800 & 3.64 & $<0.001$ \\
\hline \multicolumn{6}{|l|}{ b) Study 3} \\
\hline Intercept & 2.28 & 0.24 & 133 & 9.45 & $<0.001$ \\
\hline Dummy control $^{\mathrm{b}}$ & 0.47 & 0.33 & 131 & 1.41 & 0.162 \\
\hline Dummy deliberation plan ${ }^{c}$ & 0.66 & 0,34 & 133 & 1.96 & 0.051 \\
\hline Losing probability & 1.19 & 0.20 & 18,316 & 6.11 & $<0.001$ \\
\hline Losing probability $\times$ dummy control $^{\mathrm{b}}$ & 0.22 & 0.27 & 18,298 & 0.830 & 0.407 \\
\hline $\begin{array}{l}\text { Losing probability } \times \text { dummy } \\
\text { deliberation plan }\end{array}$ & 0.29 & 0.27 & 18,298 & 1.06 & 0.288 \\
\hline
\end{tabular}

a Deliberation plan $=1$, spontaneity plan $=1$.

b Control $=1$, spontaneity plan $=0$, deliberation plan $=0$.

${ }^{c}$ Control $=0$, spontaneity plan $=0$, deliberation plan $=1$.

2.3.2.2. Response times. A mixed linear model (see Table 2b) with the plan condition and the probability of losing as predictors and response times as the dependent variable demonstrated a significant main effect of the probability of losing, indicating that participants took longer to react if the cards suggested a probability of losing. The interaction of probability of losing and the plan condition was not significant. As ex pected, response times were fastest for the spontaneity plan group $(M=2.79 \mathrm{~s})$, slower for the control group $(M=3.15 \mathrm{~s})$, and slowest for the deliberation plan group $(M=3.37 \mathrm{~s})$. However, only the com parison of the spontaneity plan group and the deliberation plan group turned out to be (marginally) significant $(p=0.051$ ), the comparison of the spontaneity plan group did not reach significance.

2.3.2.3. Investment decision. The linear mixed logit model depicting the analysis of participants' investment decisions is summarized in Table $1 b$. For the investment decisions after the initial choice, participants' re sponses in the control group did not differ from those given in the spon taneity plan group. As in Study 2, there was a main effect of probability of losing, indicating that participants in all conditions were more likely to opt out if they were likely to lose a given turn. Importantly, as indicat ed by an interaction effect of plan condition and probability of losing, this tendency was strongest for those participants who made delibera tion plans. Responses of participants in the deliberation plan group were significantly more in line with the probability of losing. Partici pants in the deliberation plan group were more likely to opt out if the probability of losing was high. The direct comparison of this interaction

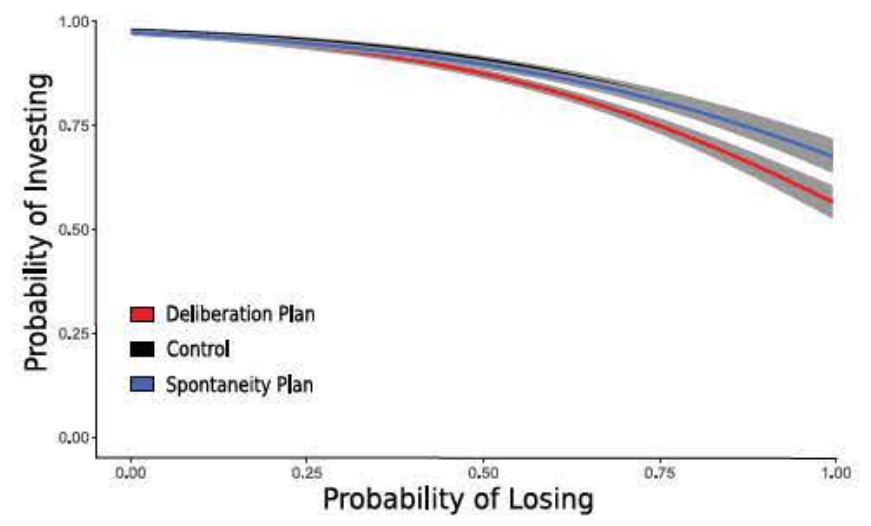

Fig. 4. Illustration of the linear mixed logit model estimating probability of investing in Study 3 depending on probability of losing, plan condition, and their interaction for all decisions after a first bet had been made. effect comparing the spontaneity plan group to the control group was not significant. The critical interaction is visualized in Fig. 4.

\subsubsection{Discussion}

Study 3 replicated the main finding of Study 2. Both studies used the variable investment poker task to investigate the impact of deliberation plans on the use of feedback information. Most importantly, partici pants in the deliberation plan group were more sensitive to the proba bility of losing in both studies than participants in the spontaneity plan group. Results for the control group in Study 3 were in between the de liberation plan group and the spontaneity plan group; however, con trol participants did not differ significantly from participants in the spontaneity plan group. These findings support our main hypothesis that deliberation plans can be used to shift information processing to wards a more thoughtful and reflective mode. The observed differences in response time further confirm this assumption showing the expected pattern with faster responses in the spontaneity plan group and slower responses in the deliberation plan group. The differences in response time patterns between Studies 2 and 3 suggest that the if then planned deliberation is indeed initiated by the specified cue. In Study 2 partici pants planned to deliberate "if the situation is unfavorable," which re sulted in longer response times for decisions with a high probability of losing. In Study 3, participants planned to deliberate "if a new card is turned up," which resulted in generally slower responses. When treating the two studies as an experimental between factor (cue: unfa vorable situation vs. new cards turned up), the response time patterns of the two studies are significantly different, $t(240.000), p=0.006$, in dicating that deliberation was initiated in line with the respective cue it was linked to.

\section{General discussion}

Research on planning by using implementation intentions has pro duced a large amount of studies indicating that making if then action plans increases the likelihood of actually initiating an intended response at the critical moment (Gollwitzer, 2014; Gollwitzer \& Sheeran, 2006). We extend the research on if then planning by providing evidence that it is also effective to prospectively plan out engaging in deliberation. We demonstrate that just like planning to perform a specific response increases the likelihood of executing this response, planning to engage in deliberation of available information increases the likelihood of doing so. We observed the consequences of this planned deliberation in three studies using two different escalation of commitment para digms. In all three studies, we found evidence that participants who planned to deliberate at a specified critical situational cue showed a re duced tendency to stick to a failing course of action compared to partic ipants without a plan (Studies 1 \&3), and compared to participants with a spontaneity plan (Studies $2 \& 3$ ). This reduced tendency to stick to a failing course of action thus seems to be the result of an increased con sideration of available information (i.e., negative feedback; Studies 2 \& 3).

We want to highlight that our results of Study 1 were obtained in a traditional, often used paradigm in research on the escalation of com mitment. However, as this paradigm uses hypothetical scenarios, we moved on and developed a novel task paradigm for Studies 2 and 3. This novel paradigm adapted from a poker game variant did not rely on false feedback and demanded to make decisions that had real mon etary consequences. Furthermore, the combination of a no plan control condition (Studies 1 \& 3) and an implementation intention control con dition favoring the opposite of deliberation (i.e., spontaneous responding; Studies 2 and 3 ) provides strong evidence for a causal effect of planned deliberation on processing information relevant to adjusting a made decision.

Our studies also suggest that escalation of commitment is related to impulsive, spontaneous processing. In line with this assumption, a shift towards an increase in deliberation resulted in less escalation as 
compared to a neutral control condition (Studies $1 \& 3$ ) and a spontane ity plan condition favoring impulsive responses (Studies $2 \& 3$ ). Thus, in contrast to previous studies using implementation intentions to reduce escalation of commitment (Henderson et al., 2007; Wieber et al., 2015), the present studies show that not only a task specific response (e.g., considering recent developments) but also a general change in the style of cognitive processing into the direction of more deliberation can reduce escalation of commitment.

The task paradigm used in Studies 2 and 3 allowed assessing deci sions in incentivized escalation situations. This has several advantages over standard paradigms used in escalation of commitment research such as hypothetical business scenarios (Fox \& Staw, 1979; Garland \& Newport, 1991; Staw, 1976), or paradigms using deception (Strube \& Lott, 1984). Because feedback in the form of revealed cards is based on randomly generated trials, no deception is necessary to create naturally occurring escalation situations. Furthermore, the within subjects design of the VIP Task used in Studies 2 and 3 allows for additional manipula tions that could be used in future studies. For instance, framing of the decisions could easily be manipulated by using different mental repre sentations of the decision outcomes (e.g., gains vs. losses), and also the costs of investments could be modified easily. In this way, the effect of different degrees of sunk costs in relation to the assigned endowment (Garland \& Newport, 1991) could be investigated. By hiding or showing the opponent's cards, the degree of certainty could also be varied. Be cause certainty as well as risk in terms of probability can be varied in the VIP Task, this new task paradigm might be useful for escalation of commitment research on risk perception and risk taking as well as to disentangle the effects of uncertainty and risk in escalation of commit ment situations. Our newly developed paradigm is very similar to real world poker games and thus could easily be adapted to investigate esca lation in social situations with real opponent players. This would be par ticularly interesting because escalation of commitment might be increased in the presence of others (Sleesman et al., 2012).

\section{Conclusion}

To conclude, we provide evidence that engaging in deliberation can be effectively planned in advance of prospective critical situations. This might be necessary in the case of important upcoming decisions that need to be based on information only available at the time the decision has to be made. Escalation of commitment is such a situation in which investments have to be reevaluated on the spot. Motivational processes drive people to stick to a failing course of action and to ignore relevant information that is available at the time of the decision. Our research suggests that planning to deliberate thoroughly is effective to increase the use of relevant available information. Even if we do not know how the situation might change or what new information might be available in the future, we can plan to deliberate and take a step back before mak ing decisions; and thus make better decisions, "knowin' what to throw away and knowin' what to keep."

Appendix 1. Mixed linear logit models estimating probability of betting in Study 2, including control variables, plan condition, probability of losing, the interaction of probability of losing and plan conditions, and the interaction of plan conditions and control variables

\begin{tabular}{lcccc}
\hline Variable & $B$ & $S E B$ & $z$ & $p$ \\
\hline Intercept $_{\text {Plan condition }}{ }^{\mathrm{a}}$ & 4.04 & 0.84 & 4.81 & $<0.001$ \\
Losing probability $_{\text {Impulsivity }}$ & 0.39 & 0.84 & 0.47 & $=0.641$ \\
Frequency of playing poker & 3.83 & 0.16 & 23.76 & $<0.001$ \\
& 4.55 & 1.72 & 2.64 & $=0.008$ \\
\hline
\end{tabular}

(continued)

\begin{tabular}{|c|c|c|c|c|}
\hline Variable & $B$ & $S E B$ & $z$ & $p$ \\
\hline Numeracy & 0.01 & 0.04 & 0.28 & $=0.776$ \\
\hline Need for cognition & 0.10 & 0.15 & 0.66 & $=0.507$ \\
\hline Age & $>0.01$ & 0.01 & 0.01 & $=0.993$ \\
\hline Sex & 0.36 & 0.19 & 1.87 & $=0.062$ \\
\hline Plan condition ${ }^{\mathrm{a}} \times$ losing probability & 0.69 & 0.16 & 4.31 & $<0.001$ \\
\hline Plan condition ${ }^{\mathrm{a}} \times$ impulsivity & 0.61 & 1.72 & 0.35 & $=0.723$ \\
\hline Plan condition ${ }^{\mathrm{a}} \times$ frequency of playing poker & 0.06 & 0.04 & 1.56 & $=0.119$ \\
\hline Plan condition ${ }^{\mathrm{a}} \times$ numeracy & 0.01 & 0.04 & 0.39 & $=0.694$ \\
\hline Plan condition ${ }^{\mathrm{a}} \times$ need for cognition & 0.13 & 0.15 & 0.84 & $=0.403$ \\
\hline Plan condition $^{\mathrm{a}} \times$ age & $>0.01$ & 0.01 & 0.14 & $=0.892$ \\
\hline Plan condition ${ }^{\mathrm{a}} \times$ sex & 0.16 & 0.19 & 0.83 & $=0.408$ \\
\hline
\end{tabular}

a Deliberation plan $=1$, spontaneity plan $=1$.

\section{References}

Abelson, R. P., \& Prentice, D. A. (1997). Contrast tests of interaction hypothesis. Psychological Methods, 2, 315-328. http://dx.doi.org/10.1037/1082-989X.2.4.315.

Achtziger, A., Bayer, U. C., \& Gollwitzer, P. M. (2012). Committing to implementation intentions: Attention and memory effects for selected situational cues. Motivation and Emotion, 36, 287-300. http://dx.doi.org/10.1007/s11031-011-9261-6.

Bates, D., Maechler, M., Bolker, B., \& Walker, S. (2015). Fitting linear mixed-effects models using lme4. Journal of Statistical Software, 67, 1-48. http://dx.doi.org/10.18637/jss. v067.i01.

Bayer, U. C., Achtziger, A., Gollwitzer, P. M., \& Moskowitz, G. B. (2009). Responding to subliminal cues: Do if-then plans facilitate action preparation and initiation without conscious intent? Social Cognition, 27, 183-201. http://dx.doi.org/10.1521/soco.2009.27. 2.183.

Birnboim, S. (2003). The automatic and controlled information-processing dissociation: Is it still relevant? Neuropsychology Review, 13, 19-31. http://dx.doi.org/10.1023/A 1022348506064 .

Bobocel, D. R., \& Meyer, J. P. (1994). Escalating commitment to a failing course of action: Separating the roles of choice and justification. Journal of Applied Psychology, 79, 360-363. http://dx.doi.org/10.1037/0021-9010.79.3.360

Brockner, J. (1992). The escalation of commitment to a failing course of action: Toward theoretical progress. The Academy of Management Review, 17, 39-61. http://dx.doi. org $/ 10.2307 / 258647$.

Cacioppo, J. T., \& Petty, R. E. (1982). The need for cognition. Journal of Personality and Social Psychology, 42, 116-131. http://dx.doi.org/10.1037/0022-3514.42.1.116.

Cacioppo, J. T., Petty, R. E., \& Feng Kao, C. (1984). The efficient assessment of need for cognition. Journal of Personality Assessment, 48, 306-307. http://dx.doi.org/10.1207/ s15327752jpa4803_13.

Cohen, A. -L., Bayer, U. C., Jaudas, A., \& Gollwitzer, P. M. (2008). Self-regulatory strategy and executive control: Implementation intentions modulate task switching and Simon task performance. Psychological Research, 72, 12-26. http://dx.doi.org/10. 1007/s00426-006-0074-2.

Dougherty, D., Mathias, C., Marsh, D., \& Jagar, A. (2005). Laboratory behavioral measures of impulsivity. Behavior Research Methods, 37, 82-90. http://dx.doi.org/10.3758/ BF03206401.

Faul, F., Erdfelder, E., Buchner, A., \& Lang, A. -G. (2009). Statistical power analyses using G*Power 3.1: Tests for correlation and regression analyses. Behavior Research Methods, 41, 1149-1160. http://dx.doi.org/10.3758/brm.41.4.1149.

Faul, F., Erdfelder, E., Lang, A. -G., \& Buchner, A. (2007). G*Power 3: A flexible statistical power analysis program for the social, behavioral, and biomedical sciences. Behavior Research Methods, 39, 175-191. http://dx.doi.org/10.3758/bf03193146.

Fox, F. V., \& Staw, B. M. (1979). The trapped administrator: Effects of job insecurity and policy resistance upon commitment to a course of action. Administrative Science Quarterly, 24, 449-471. http://dx.doi.org/10.2307/2989922.

Garland, H., \& Newport, S. (1991). Effects of absolute and relative sunk costs on the decision to persist with a course of action. Organizational Behavior and Human Decision Processes, 48, 55-69. http://dx.doi.org/10.1016/0749-5978(91)90005-e.

Gollwitzer, P. M. (1993). Goal achievement: The role of intentions. European Review of Social Psychology, 4, 141-185. http://dx.doi.org/10.1080/14792779343000059.

Gollwitzer, P. M. (1999). Implementation intentions: Strong effects of simple plans. American Psychologist, 54, 493-503. http://dx.doi.org/10.1037/0003-066x.54.7.493.

Gollwitzer, P. M. (2014). Weakness of the will: Is a quick fix possible? Motivation and Emotion, 38, 305-322. http://dx.doi.org/10.1037/e642622013-004.

Gollwitzer, P. M., \& Brandstätter, V. (1997). Implementation intentions and effective goal pursuit. Journal of Personality and Social Psychology, 73, 186-199. http://dx.doi.org/10. 1037//0022-3514.73.1.186.

Gollwitzer, P. M., \& Oettingen, G. (2016). Planning promotes goal striving. In K. Vohs, \& R. Baumeister (Eds.), Handbook of self-regulation: Research, theory, and applications (pp. 223-244) (3rd ed.). New York: Guilford. http://dx.doi.org/10.1176/ps.2006.57. 4.585a (2nd ed.)

Gollwitzer, P. M., \& Sheeran, P. (2006). Implementation intentions and goal achievement: A meta-analysis of effects and processes. Advances in Experimental Social Psychology, 38, 69-119. http://dx.doi.org/10.1016/S0065-2601(06)38002-1.

Henderson, M. D., Gollwitzer, P. M., \& Oettingen, G. (2007). Implementation intentions and disengagement from a failing course of action. Journal of Behavioral Decision Making, 20, 81-102. http://dx.doi.org/10.1002/bdm.553.

Kuznetsova, A., Brockhoff, P. B., \& Christensen, R. H. B. (2015). ImerTest: Tests for random and fixed effects for linear mixed effect models (lmer objects of lme4 package). $R$ package version, 2. 0-29. http://CRAN.R-project.org/package=lmerTest 
Lipkus, I. M., Samsa, G., \& Rimer, B. K. (2001). General performance on a numeracy scale among highly educated samples. Medical Decision Making, 21, 37-44. http://dx.doi. org/10.1177/0272989x0102100105.

Martiny-Huenger, T., Thürmer, J. L., Issa, M., \& Gollwitzer, P. M. (2011). Über die Unterstützung reflektiver Verhaltensdeterminanten (On supporting reflective behavioral determinats). Psychologische Rundschau, 62, 179-187.

Parks-Stamm, E. J., Gollwitzer, P. M., \& Oettingen, G. (2007). Action control by implementation intentions: Effective cue detection and efficient response initiation. Social Cognition, 25, 248-266. http://dx.doi.org/10.1521/soco.2007.25.2.248.

Peirce, J. W. (2007). PsychoPy-Psychophysics software in Python. Journal of Neuroscience Methods, 162, 8-13. http://dx.doi.org/10.1016/j.jneumeth.2006.11.017.

Peters, E., Västfjäll, D., Slovic, P., Mertz, C. K., Mazzocco, K., \& Dickert, S. (2006). Numeracy and decision making. Psychological Science, 17, 407-413. http://dx.doi.org/10.1111/j. 1467-9280.2006.01720.x.

Phillips, W. J., Fletcher, J. M., Marks, A. D., \& Hine, D. W. (2016). Thinking styles and decision making: A meta-analysis. Psychological Bulletin, 142, 260-290. http://dx.doi.org/ $10.1037 /$ bul0000027.

Rogers, K. (1978). The gambler. Liberty.

Rosenthal, R., \& Rosnow, R. L. (1985). Contrast analysis: Focused comparisons in the analysis of variance. Cambridge: Cambridge University Press. http://dx.doi.org/10.1037/ 026845.

Siler, K. (2010). Social and psychological challenges of poker. Journal of Gambling Studies, 26, 401-420. http://dx.doi.org/10.1007/s10899-009-9168-2.

Sleesman, D. J. Conlon, D. E. McNamara, G. \& Miles, J. E. (2012). Cleaning up the big muddy: A meta-analytic review of the determinants of escalation of commitment. Academy of Management Journal, 55, 541-562. http://dx.doi.org/10.5465/amj.2010. 0696.

Soman, D. (2008). Framing, loss aversion, and mental accounting. In D. J. Koehler, \& N. Harvey (Eds.), Blackwell handbook of judgment and decision making (pp. 379-398). Boston: Blackwell Publishing Ltd. http://dx.doi.org/10.1002/9780470752937.ch19.

Staw, B. M. (1976). Knee-deep in the big muddy: A study of escalating commitment to a chosen course of action. Organizational Behavior and Human Performance, 16, 27-44. http://dx.doi.org/10.1016/0030-5073(76)90005-2.
Stewart, B. D., \& Payne, B. K. (2008). Bringing automatic stereotyping under control: Implementation intentions as efficient means of thought control. Personality and Socia Psychology Bulletin, 34, 1332-1345. http://dx.doi.org/10.1177/0146167208321269.

Strube, M. J., \& Lott, C. L. (1984). Time urgency and the Type A behavior pattern: Implications for time investment and psychological entrapment. Journal of Research in Personality, 18, 395-409. http://dx.doi.org/10.1016/0092-6566(84)90023-0.

von Neumann, J., \& Morgenstern, O. (2007/1944). Theory of games and economic behavior Princeton, NJ, U.S.A.: Princeton University Press. http://dx.doi.org/10.1515/ 9781400829460

Webb, T. L, \& Sheeran, P. (2004). Identifying good opportunities to act: Implementation intentions and cue discrimination. European Journal of Social Psychology, 34, 407-419. http://dx.doi.org/10.1002/ejsp.205.

Webb, T. L., \& Sheeran, P. (2007). How do implementation intentions promote goal attainment? A test of component processes. Journal of Experimental Social Psychology, 43, 295-302. http://dx.doi.org/10.1016/j.jesp.2006.02.001.

Wieber, F., \& Sassenberg, K. (2006). I can't take my eyes off of it-Attention attraction effects of implementation intentions. Social Cognition, 24, 723-752. http://dx.doi.org/ 10.1521/soco.2006.24.6.723.

Wieber, F., Thürmer, J. L., \& Gollwitzer, P. M. (2015). Attenuating the escalation of commitment to a faltering project in decision-making groups an implementation intention approach. Social Psychological and Personality Science, 6, 587-595. http://dx.doi. org/10.1177/1948550614568158.

Wong, K. F. E. (2005). The role of risk in making decisions under escalation situations. Journal of Applied Psychology, 54, 584-607. http://dx.doi.org/10.1111/j.1464-0597. 2005.00236.x.

Wong, K. F. E., \& Kwong, J. Y. (2007). The role of anticipated regret in escalation of commitment. Journal of Applied Psychology, 92, 545-554. http://dx.doi.org/10.1037/00219010.92 .2 .545 